\section{Therapy Using Filter Needles}

To the Editor:

I would like to inquire about your recommendations regarding the use of filter needles for drawing up of medications contained in ampules that are to be given IV push or IM.

There has been much controversy regarding this issue in regards to cost versus quality and need of use. Our nursing staff has been experimenting with these and has found that they do filter foreign particles of glass and such, but the infection control committee questions their reliability in effective use in comparison to cost. I have been unable to find any literature that discusses the issue as to pros and cons. In conversations with other hospitals, it seems that the use of filter needles is not being practiced, but since I have approached the various IV teams and infection control committee, they now wish to know more about the subject.

I would appreciate your recommendations on the use of filter needles and perhaps some reference material that our hospital can study.

\author{
Sherry Warren, R.N. \\ Infection Control Nurse \\ Doctors Memorial Hospital \\ Tyler, Texas
}

The preceding letter was referred to Sue Crow, R.N., M.S.N., Associate Editor of Infection Control, for a reply.

At present there are no published studies that show a comparison be- tween rates of infection related to IV therapy using filter needles to infection rates where filter needles are not used. Therefore, the Centers for Disease Control (CDC) does not recommend filter needles from an infection control perspective.

The National Intravenous Therapy Association (NITA), however, recommends that filter needles ( $1 \mu$ in size) be used anytime that glass ampules are involved. Their recommendation is based on studies on the efficacy of the needle filtering out particulate matter. They recommend that the filter needle be used even if there is an in-line filter in the IV system.

Since there are different views from two different organizations and because these issues are not the same, it becomes the responsibility of the individual hospital to decide the quality of patient care they will provide and to make their own decision as to whether they will or will not use such devices.

$$
\begin{array}{r}
\text { Sue Crow, R.N., M.S.N. } \\
\text { Nurse Epidemiologist } \\
\text { Louisiana State University } \\
\text { Medical Center } \\
\text { Shreveport, Louisiana }
\end{array}
$$

\section{Peer Review in Nursing and Medical Journals}

To the Editor:

I read with interest Dr. Harry Nottebart's views on "peer review" journals
(Readers' Forum, Infection Control November/December 1982). Since he does not specifically refer to medical journals, and since the article appears in a quasi-multidisciplinary journal, I will assume his statements were meant to include nursing journals.

Since Dr. Nottebart knows of no listings of journals designating which are peer review, or refereed, and which are not, it seems that perhaps the nursing profession is a step ahead of the medical profession in attempting to provide this distinction for its members.

Two rather recent articles which address this issue have appeared in nursing journals, Nursing Outlook (September 1981) and Image, the official publication of Sigma Theta Tau, National Honor Society of Nursing. The authors of these articles share some of Dr. Nottebart's views on the definition and importance of a "refereed" journal, but have at least raised some questions and provided some information for the members of the nursing profession.

For what it's worth, Nursing Outlook and Image are both refereed journals.

Sandy Pirwitz, R.N. Infection Control Coordinator St. Vincent Hospital \& Medical Center Toledo, Ohio

Dr. Harry C. Nottebart, author of the article in question, was invited to respond.

I was delighted to get a copy of Sandy Pirwitz's letter to Infection Control. I do see a few nursing journals but was not familiar with either of the articles to which she alluded. 1,2 